\title{
Novel Sequential Rotated 2x2 Array Notched Circular Patch Antenna
}

\author{
M L S N S Lakshmi, Habibulla Khan and B T P Madhav* \\ Department of ECE, $K$ L University, AP, India
}

Received 5 November 2015; Accepted 21 November 2015

\begin{abstract}
This article presents a novel high gain rotated circular patch antenna operating at S-band. Circular patches are arranged with probe feeding in a particular order to get circular polarization. By employing sequential rotation technique, the proposed antenna is giving an impedance bandwidth of more than $40 \%$ (return loss less than $-10 \mathrm{~dB}$ ) and $3 \mathrm{~dB}$ axial ratio bandwidth of $15 \%$ in the operating band with peak gain around $13 \mathrm{~dB}$. Array antenna is fabricated on RT-duroid substrate and the measured results are showing good agreement with the simulation results.
\end{abstract}

Keywords: Array, Circular Patch, Notch, Sequential Rotation.

\section{Introduction}

Microstrip antenna technology has started its rapid development in the late 1970s. Basic microstrip antenna elements and arrays were fairly well established in terms of design and modelling [1]. In the recent years printed antennas have been largely studied due to their advantages over other radiating systems, such as light weight, reduced size, low cost, conformability and possibility of integration with active devices. Circularly polarized antennas are gaining their demand with microstrip technology. The main advantage of using circular polarization is that regardless of receiver orientation, it will always receive a component of the signal [2-4]. This results an advantage such that wave having an angular variation. Generally in order to polarize circularly using dual feeding methods, two orthogonal modes are equally excited with $90^{\circ}$ phase difference between them.

Different antenna configurations are proposed by the researchers for different applications in the communication [5-10]. In general two types of antennas used for WLAN applications, fixed WLAN base stations or access points, and the other is for mobile communication terminals. Circular polarized antennas are very attractive for this because, they can overcome the multipath fading problem, thus enhance the system performance, especially indoor WLAN operation. Currently, the most commonly used WLAN system is the IEEE $802.11 \mathrm{~b}$ System. A key requirement of WLAN system is that it should be low profile, where it is almost invisible to the user [11-13]. For this reason, the microstrip patch antennas are the choice for WLAN use due to their small real estate area and the ability to be designed to blend into the surroundings [14-15].

\section{Antenna Geometry}

* E-mail address: btpmadhav@kluniversity.in ISSN: 1791-2377 @ 2015 Kavala Institute of Technology. All rights reserved.
The notched circular patch and other circularly polarized antennas tend to suffer from high cross-polarization levels, especially away from resonance and off broadside. One way of improving the axial ratio is to use a number, say $\mathrm{N}$, of these antennas, identical within the limits imposed by the manufacturing tolerances, together in an array, and rotate them in sequence. The differential physical rotation angle and phase shift are both $\mathrm{p} \pi / \mathrm{N}$, where $\mathrm{p}$ is an integer such that $0<\mathrm{p}<\mathrm{N}$. The elements are excited with equal amplitude which results in the polarization ellipses of the individual elements being superimposed to yield near perfect circular polarization on boresight at the centre frequency. In the simplest case of a two element array, the elements are rotated by $90^{\circ}$ and excited with relative phases of $+90^{\circ}$ or $90^{\circ} \mathrm{s}$, depending on the required polarization sense, i.e. LHC or RHC. In many cases, a sequentially rotated sub-array may be used as a building block for a much larger array. There are many possible arrangements of sequentially rotated arrays, especially if more than four elements are used. Different configurations can be used to reduce the crosspolarization from various sources, such as multiple reflections, feed phase errors and higher order modes.

Each patch element uses only a single feed pin which is fed from behind the ground plane. A feed network which incorporates all the necessary phasing and impedance transformations may be integrated onto the back of the ground plane. For the design used in Magus, no feed network is used and each element is fed directly with the appropriate phase.

Fig 1 shows the typical orientation of $2 \times 2$ notched circular array patch antenna with coaxial feeding. Table 1 shows the dimensional characteristics of the antenna in $\mathrm{mm}$.

The design guidelines for the patch dimensions are the same as for a single patch element. The spacing between array elements is typically of the order of half a free-space wavelength or slightly larger, but this may rather be determined by the pattern requirements of the overall array. To switch polarization, the polarization of the individual patch should be modified (in this case by changing the sign of the feed rotation angle) and changing the sign of the 
M L S N S Lakshmi, Habibulla Khan and B T P Madhav /

Journal of Engineering Science and Technology Review 8 (4) (2015) 73- 77

relationship between the element rotation angle and port phase.
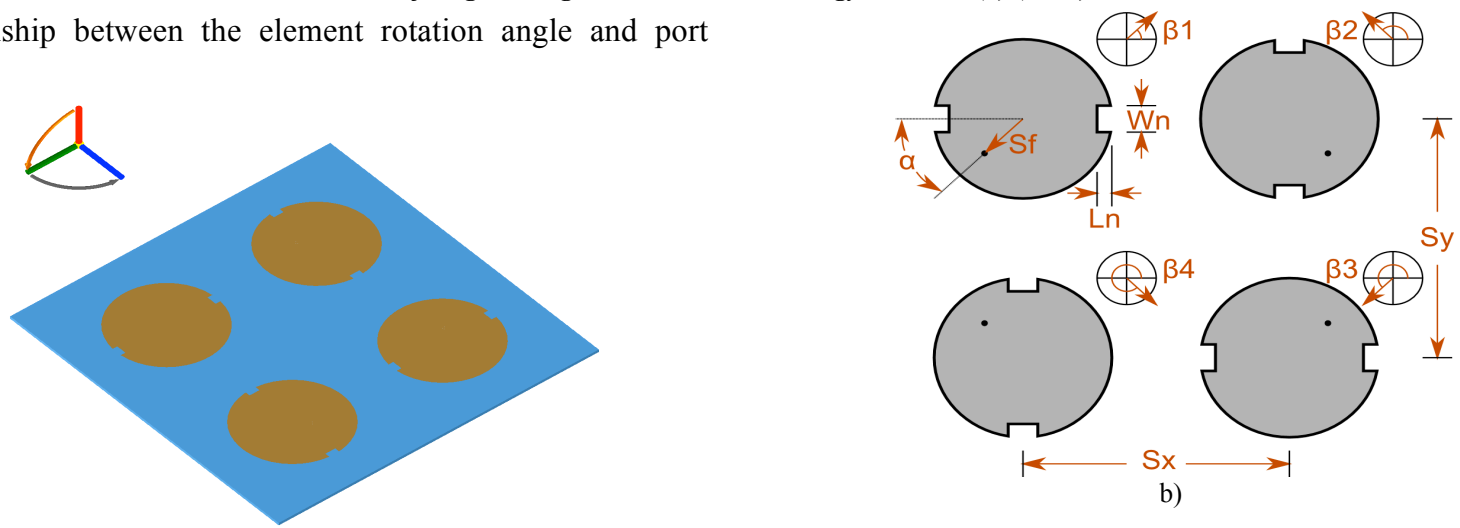

b)

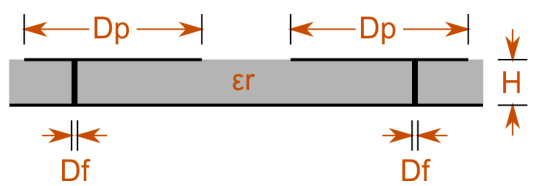

c)

Fig 1. (a) $2 X 2$ Circular Array Patch, (b) Top View, (c) Side View

Table 1. Antenna Parameters

\begin{tabular}{|c|c|c|c|c|c|c|c|}
\hline S.No & Parameter & Notation & Dimensions & S.No & Parameter & Notation & Dimensions \\
\hline 1 & Patch diameter & $\mathrm{Dp}$ & $46.75 \mathrm{~mm}$ & 11 & Element 1 Rotation angle & $\beta 1$ & $0^{0}$ \\
\hline 2 & Notch Length & $\mathrm{Ln}$ & $2.281 \mathrm{~mm}$ & 12 & Element 2 Rotation angle & $\beta 2$ & $-90^{0}$ \\
\hline 3 & Notch width & Wn & $4.562 \mathrm{~mm}$ & 13 & Element 3 Rotation angle & $\beta 3$ & $-180^{\circ}$ \\
\hline 4 & Diameter of feed pin & Df & $1.224 \mathrm{~mm}$ & 14 & Element 4 Rotation angle & $\beta 4$ & $-270^{\circ}$ \\
\hline 5 & Offset of feed pin & Sf & $7.083 \mathrm{~mm}$ & 15 & Element 1 port phase & $\beta 1$ & $0^{0}$ \\
\hline 6 & Feed pin rotation angle & $\alpha$ & $45^{0}$ & 16 & Element 2 port phase & $\beta 2$ & $90^{\circ}$ \\
\hline 7 & $\begin{array}{l}\text { Permittivity of } \\
\text { substrate }\end{array}$ & $\varepsilon_{\mathrm{r}}$ & 2.2 & 17 & Element 2 port phase & $\beta 3$ & $180^{\circ}$ \\
\hline 8 & Height of the substrate & $\mathrm{h}$ & $1.6 \mathrm{~mm}$ & 18 & Element 3 port phase & $\beta 4$ & $270^{\circ}$ \\
\hline 9 & Patch spacing & Sx & $70.12 \mathrm{~mm}$ & 19 & Centre Frequency & $\mathrm{f}_{0}$ & $2.45 \mathrm{GHz}$ \\
\hline 10 & Patch spacing & Sy & $70.12 \mathrm{~mm}$ & 20 & & & \\
\hline
\end{tabular}

- For right-hand circular polarization, the phase shifts of the excitations are opposite to those of the patch rotation angles

- For left-hand circular polarization, the phase shifts of the excitations are identical to those of the patch rotation angles

\section{Results and Discussion}

Consider the broadside radiation of two elliptically polarized antenna elements excited with equal amplitude, where the second element has been rotated by $90^{\circ}$ and driven at $-90^{\circ}$ with respect to the first element. The polarization ellipses of the elements then lie at $90^{\circ}$ with respect to one another. The quadrature feed phasing then ensures that the instantaneous E-field vectors combine such that the two ellipses add to form a circle, thus producing perfect circular polarisation at broadside. This will be the case even if the antenna elements are linearly polarized. Fig 2 shows the return loss curve and VSWR curve for the proposed antenna. It is been observed that the antenna is showing bandwidth of $800 \mathrm{MHz}$ between (2.4 to $2.5 \mathrm{GHz}$ ) and VSWR of $2: 1$.

The input impedance of each patch is similar to that of an isolated patch provided the mutual coupling is low. Depending on the feed network used, the array may have a lower input reflection coefficient than that of a single patch, and a significantly greater impedance bandwidth. The patch diameter, notch width and notch length were $0.365 \lambda$,
$0.01965 \lambda$ and $0.03935 \lambda$ respectively. The plots shown below are for a patch designed for a substrate with a $\varepsilon r$ of 2.2 and substrate height of $1.6 \mathrm{~mm}$. Fig 3 shows the input impedance of the antenna with change in frequency and smith chart. An impedance of $50 \mathrm{ohms}$ can be observed from the below figure at the operating frequency.

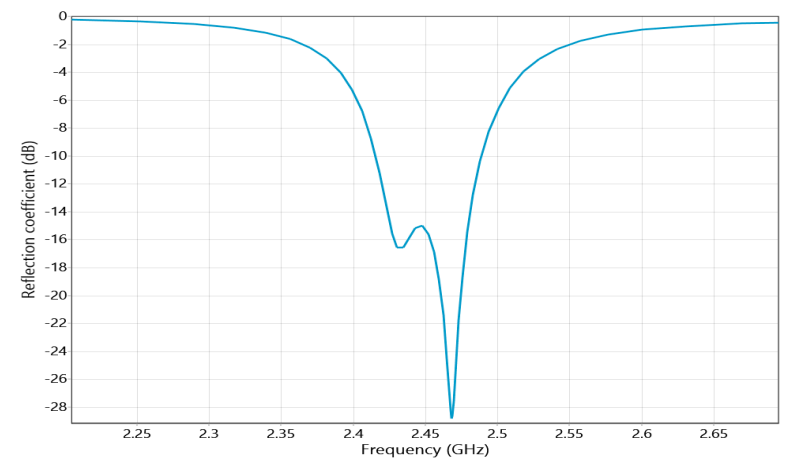

a)

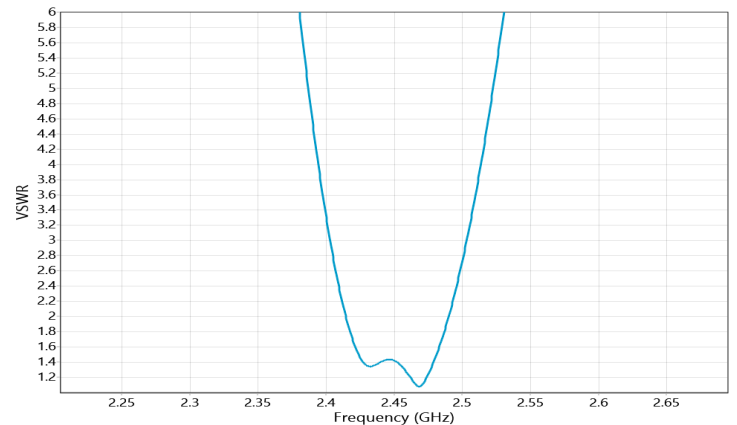

b)

Fig 2. (a) Returnloss Vs Frequency, (b) VSWR Vs Frequency 


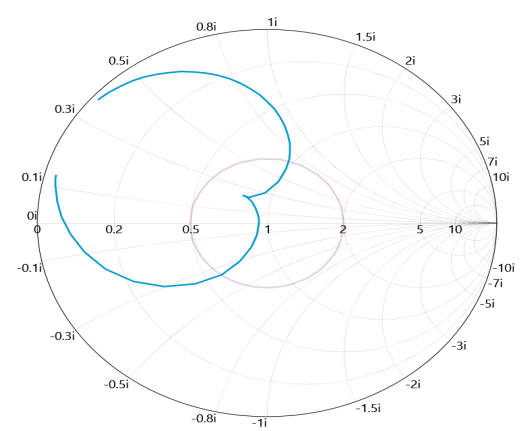

a)

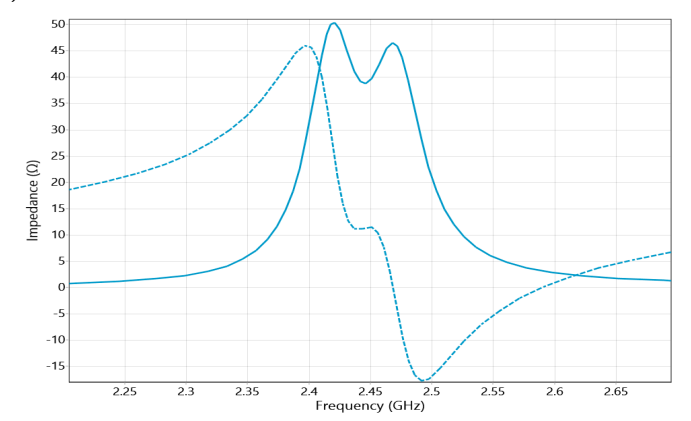

b)

Fig 3. (a) Smith Chart, (b) Impedance Vs Frequency

For ideal element phasing, the broadside radiation should in theory have perfect circular polarisation. At the centre frequency, the polarisation purity is high over a wide angular range about broadside. When looking at radiation pattern parallel to the array axes, the angular range of good axial ratio decreases slowly on either side of the resonant frequency. However, for the pattern at $45^{\circ}$ to the main axes, this angle decreases fairly rapidly. However, compared with a single patch, the axial ratio is improved and this is done over a greater frequency range and angular range. Fig 4 shows the radiation characteristics of the antenna in two dimensional view and in polar coordinates. Fig 5 shows the antenna horizontal gain with frequency and it is around 10 $\mathrm{dB}$ at the operating band. Fig 6 shows the right hand circular polarized gain of the antenna with peak realized gain of 13 $\mathrm{dB}$ at desired frequency. Fig 7 shows the axial ratio of the antenna in two dimensional plane with change in frequency. A peak realized vertical gain of $10 \mathrm{~dB}$ can be observed from the 3D plot of Fig 7.

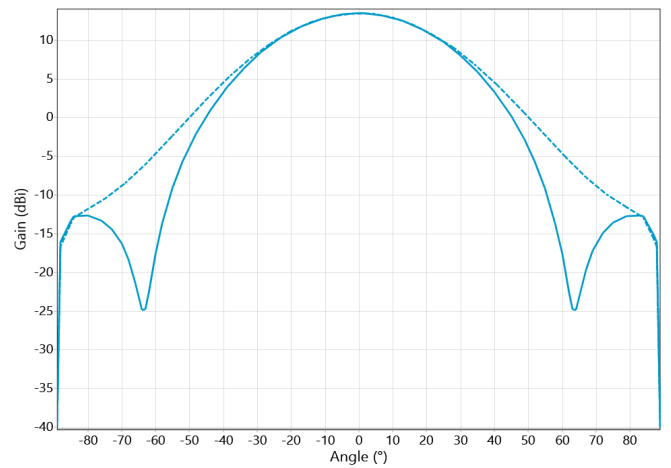

a)

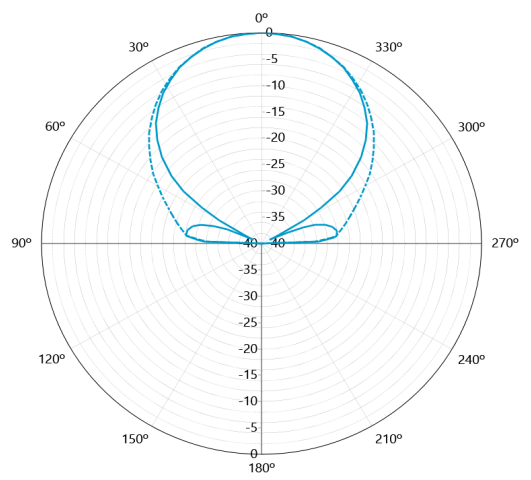

b)

Fig 4. (a) 2D-Gain Total, (b) Gain Total in Polar Coordinates

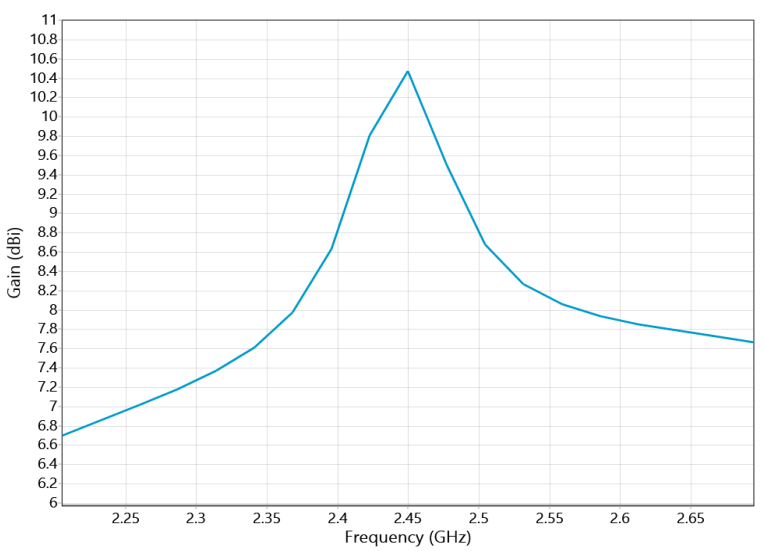

a)

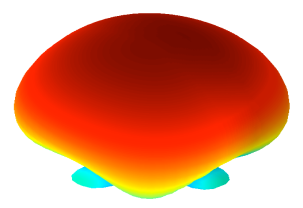

b)

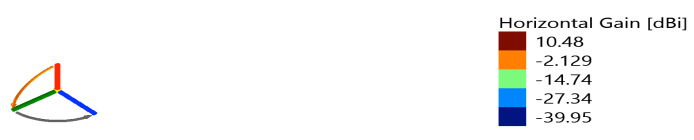

Fig 5. (a) Frequency Vs Gain, (b) Gain in 3D

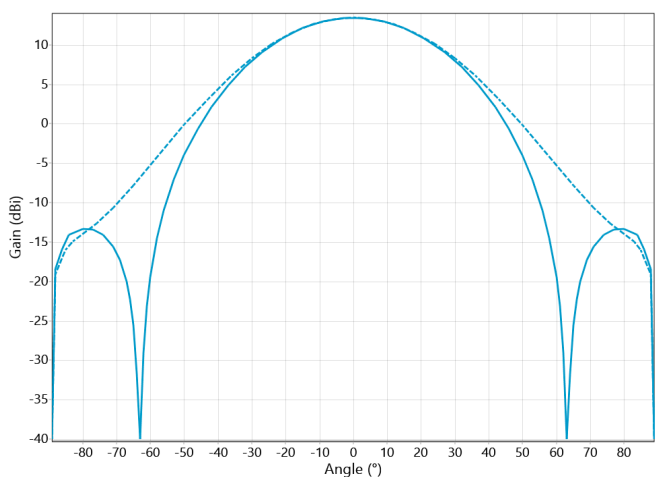

a) 
M L S N S Lakshmi, Habibulla Khan and B T P Madhav /

Journal of Engineering Science and Technology Review 8 (4) (2015) 73- 77
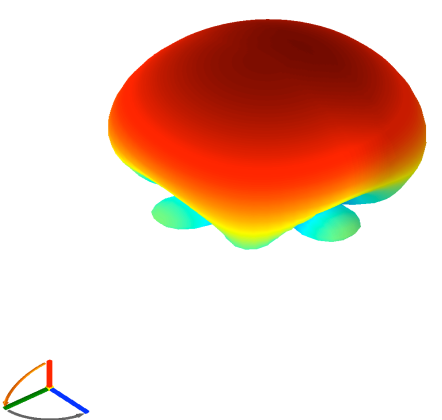

b)

Fig 6. (a) RHC gain in 2D, (b) RHC gain in 3D

Fig 8 shows the typical axial ratio patterns at different frequencies and its distribution with color scaling on other side. Fig 9 shows the axial ratio versus frequency at centre frequency and on and off broadside at theta $20^{\circ}$ and phi $0^{\circ}$ and theta $20^{\circ}$ and phi $45^{\circ}$. Figure 10 shows the proposed antenna model fabricated prototype on RT-duroid substrate. The measured results are taken from ZNB 20 vector network analyzer and observed almost same results when compared with simulation results.

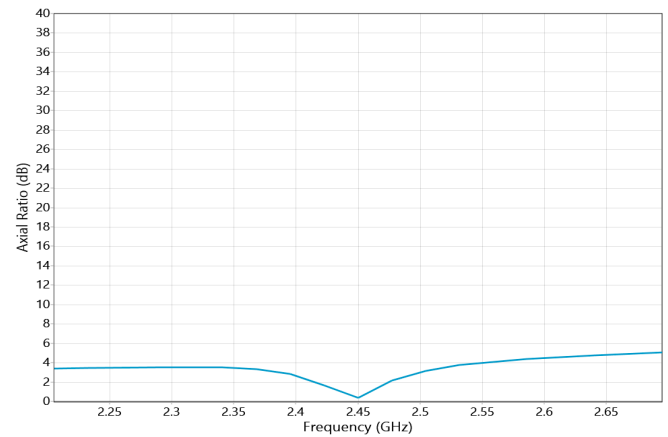

a)
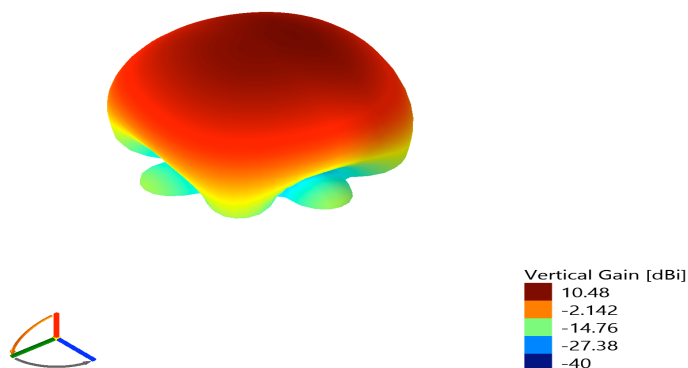

b)

Fig 7. Axial Ratio Vs Frequency, (b) Vertical gain in 3D
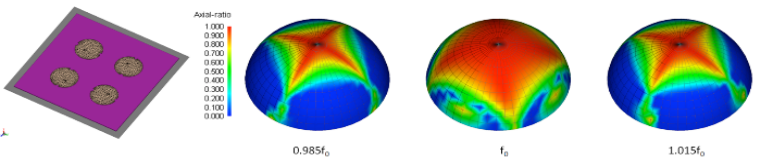

Fig 8. 3D-Axial ratio patterns at different frequencies

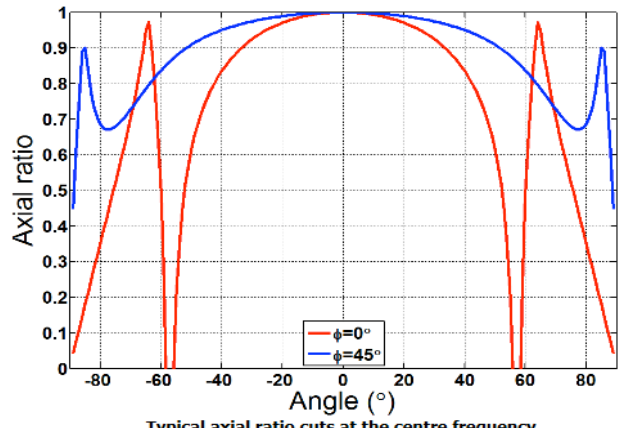

a)

Typical axial ratio cuts at the centre frequency

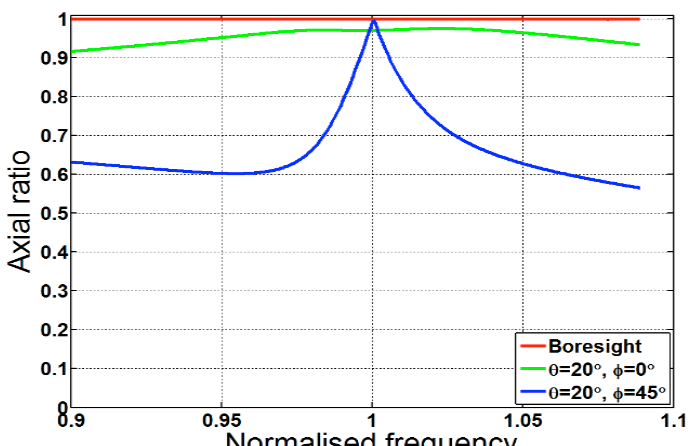

b)

Fig 9. Axial ratio Vs Frequency (a) Centre Frequency, (b) On and off Broadside

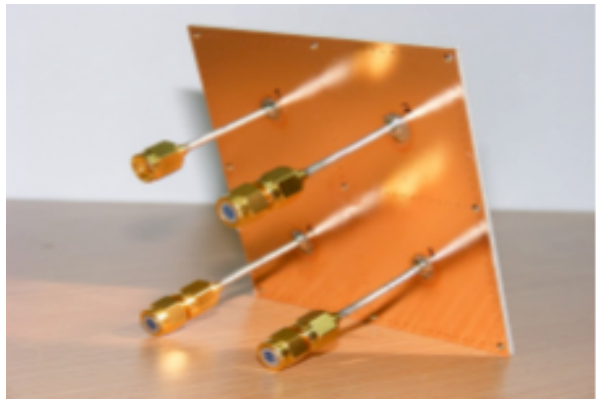

Fig 10. Prototyped Antenna

Conclusion: A circularly polarized $2 \times 2$ array notched circular patch antenna is designed to operate at WLAN applications. Proposed antenna is showing gain more than 13 $\mathrm{dB}$ and axial ratio bandwidth of $15 \%$ in the operating band. By taking a special sequential rotation technique, the proposed antenna is producing an impedance bandwidth of more than $40 \%$ at the resonant frequency. Prototyped antenna model on RT-duroid substrate is having good matching with simulation results, which motivates the applicability of the current antenna in the desired band of operation.

Acknowledgements: Authors likes to express their gratitude towards the Department of ECE and management of K L University for their continuous support and encouragement during this work.

\section{References}

1. B.T.P.Madhav, Suraj Chhatkuli, A. Manikantaprasanth, Y. Bhargav, U. Dinesh Naga Venkata Sai, Syed Feeraz, "Measurement of Dimensional Characteristics of Microstrip
Antenna based on Mathematical Formulation", International Journal of Applied Engineering Research, ISSN 0973-4562, Volume 9, Number 9, March-2014, pp. 1063-1074. 
M L S N S Lakshmi, Habibulla Khan and B T P Madhav /

Journal of Engineering Science and Technology Review 8 (4) (2015) 73- 77

2. T.-C. Yo, C.-M. Lee, C.-M. Hsu, and C.-H. Luo, "Compact circularly polarized rectenna with unbalanced circular slots," IEEE Trans. AntennasPropag., vol. 56, no. 3, pp. 882-886, Mar. 2008.

3. Nasimuddin, X. Qing, and Z. N. Chen, "A compact circular polarized cross-shaped slotted microstrip antenna," IEEE Trans. Antennas Propag., vol. 60, no. 3, pp. 1584-1588, Mar. 2012

4. K.-F. Tong and T.-P. Wong, "Circularly polarized U-slot antenna," IEEE Trans. Antennas Propag., vol. 55, no. 8, pp. 2382-2385, Aug. 2007.

5. B.T.P. Madhav, V.G.K.M. Pisipati, Habibulla Khan, V.G.N.S. Prasad, K. Praveen Kumar, K.V.L. Bhavani and P.V. Datta Prasad, "Microstrip 2x2 Square Patch Array Antenna on K15 Liquid Crystal Substrate", International Journal of Applied Engineering Research, ISSN 0973-4562 Volume 6, Number 9 (2011) pp. 1099 1104

6. B.T.P. Madhav, S.S. Mohan Reddy, J. Ravindranath Chowdary,V Vinod Babu, S.S. Satya Parthiva, S. Kalyana Saravana, "Analysis of Dual Feed Asymmetric Antenna", International Journal of Applied Engineering Research, ISSN 0973-4562 Volume 8, Number 4, June-2013, pp. 361-367. (FIST)

7. Sarat K Kotamaraju, B T P Madhav, B Anjaneyulu, N Ananda Rao, K Vijaya Vardan, "Coaxial Fed Rotated Stacked Patch Antenna", International Journal of Applied Engineering Research, ISSN 09734562, Volume 8, Number 15, (2013), pp. 1873-1879. IF:0.1.

8. B T P Madhav, J Sowjanya, V Swathi, P Tanmayee, "Circular Array Antenna Synthesis based on Element Spacing", International Journal of Applied Engineering Research, ISSN 0973-4562, Volume 9, Number 20, Sep-2014, pp. 6959-6965.

9. D S Ramkiran, B T P Madhav, Nimmagadda Haritha, R Sree Ramya, Kalyani M. Vindhya, Sai P Abhishek, “ Design and analysis of microstrip slot array antenna configuration for bandwidth enhancement", Leonardo Electronic Journal of Practices and Technologies, ISSN 1583-1078, Issue 25, July-December 2014, pp 72-83.

10. Sri Jaya Lakshmi, Habibulla Khan, B T P Madhav, Design and analysis of high gain array antenna for wireless communication applications, Leonardo Electronic Journal of Practices and Technologies, ISSN 1583-1078, Issue 26, January-June 2015, pp 89-102.

11. B T P Madhav, Harish Kaza, Thanneru Kartheek, Vidyullatha Lakshmi Kaza, Sreeramineni Prasanth, K S Sanjay Chandra Sikakollu, Maneesh Thammishetti, Aluvala Srinivas, K V L Bhavani, Novel Printed Monopole Trapezoidal Notch Antenna with S-Band Rejection, Journal of Theoretical and Applied Information Technology, ISSN: 1992-8645, Vol 76, No 1, 2015, Pp 42-49.

12. B.T.P. Madhav, Harish Kaza, Jagadish Kumar Vaka, K. Sravan Kumar, N. Sriharsha, J. Jaswanth Kumar, D.S. Siddharth and D. Sai Teja Reddy, " Design and Analysis of Compact Coplanar Wave Guide Fed Asymmetric Monopole Antennas", Research Journal of Applied Sciences, Engineering and Technology 10(3): 247-252, Jun-2015.

13. B T P Madhav, K Sai ram, M Deepika, V Naresh, "Circularly Polarized Koch Fractal Triband Antenna for Communication Applications" ARPN Journal of Engineering and Applied Sciences, ISSN: 1819-6608, Vol 10, No 14, Aug-15, pp 5795-5801.

14. W.S. Chen, C. K. Wu, and K. L. Wong, "Compact circularly polariszd microstrip antenna with bent slots," Electron. Lett., vol 34, pp. 1278-1279, Jun. 25, 1998.

15. M.M.Alam,"Microstrip antenna array with four port Butler Matrix for switched beam base station application," in Proc. Int. Conf Comput. Inf.Technol. Dhaka, Bangladesh, Dec.2009, pp.531-534. 